\title{
THE GEOID AND QUASIGEOID OF SÃO PAULO STATE USING THE UPDATED GRAVIMETRIC DATA AND THE 2018 BVRF
}

\section{O geoide e o quase-geoide do estado de São Paulo usando os dados gravimétricos atualizados e a realização da RVRB de 2018}

\author{
Valéria Cristina Silva $1^{1}$ - ORCID: 000-0003-1499-6956
}

Flavio Guilherme Vaz de Almeida Filho $2^{1}$ - ORCID: 0000-0002-8111-3204

Denizar Blitzkow $3^{1,2}$ - ORCID: 0000-0003-1412-3063

Ana Cristina Oliveira Cancoro de Matos $4^{2}$ - ORCID: 0000-0002-0040-588X

${ }^{1}$ Universidade de São Paulo, Departamento de Engenharia de Transportes, São Paulo - São Paulo, Brasil.

E-mail:vsilva2@usp.br; flaviovaz@usp.br; dblizko@usp.br

${ }^{2}$ Centro de Estudos de Geodesia, CENEGEO, São Paulo - São Paulo, Brasil.

E-mail: acocmatos@gmail.com

Received in September $28^{\text {th }} 2020$

Accepted in March $8^{\text {th }} 2021$

\begin{abstract}
:
The combination of physical and geometric heights, required for geodetic purposes, uses Global Geopotential Models (GGMs), local geoid, or quasigeoid models. The geoid height and the height anomaly, provided by GGMs, are not accurate enough for most engineering applications. Considering the normal height system of Brazil and the physical concepts of the involved reference surfaces, a quasigeoid model is more appropriate than the current Brazilian geoid model MAPGEO2015. This paper shows the determination of the geoid and the quasigeoid models for São Paulo state using the updated gravimetric data and the new system of the normal height of the 2018 Brazilian Vertical Reference Frame (BVRF). The computation of the quasigeoid model was performed by numerical integration through the Fast Fourier Transform (FFT). The Molodensky gravity anomaly was determined in a $5^{\prime}$ grid and reduced and restored using the Residual Terrain Model (RTM) technique and the XGM2019e GGM truncated at degree and order 250 and 720. The geoid model was derived from the Bouguer gravity anomalies. The quasigeoid model validation has shown a Root Mean Square (RMS) difference of $18 \mathrm{~cm}$ compared with the Global Positioning System (GPS) measurements in the levelling network.
\end{abstract}

Keywords: Height; Geoid; Quasigeoid; São Paulo state.

\section{Resumo:}

A combinação entre as altitudes físicas e geométricas, necessárias para fins geodésicos, utiliza Modelos Global do Geopotencial (MGGs), ou modelos geoidal e quase geoidal locais. A ondulação

How to cite this article: SILVA, V.C.; ALMEIDA, F.; BLITZKOW, D.; MATOS, A.C. The geoid and quasigeoid of São Paulo state using the updated gravimetric data and the 2018 BVRF. Bulletin of Geodetic Sciences. 27(2): e2021018, 2021. 
geoidal e a anomalia de altura, fornecidas pelos MGGs, não são acuradas o suficiente para a maioria das aplicações de engenharia. Considerando o atual sistema de altitude normal do Brasil e os conceitos físicos das superfícies de referência envolvidas, um modelo quase-geoidal é mais apropriado que o atual modelo geoidal brasileiro, MAPGEO2015. Este trabalho mostra a determinação dos modelos geoidal e quase-geoidal para o estado de São Paulo utilizando os dados gravimétricos atualizados e o novo sistema de altitude normal da realização de 2018 da Rede Vertical de Referência do Brasil (RVRB). O cálculo do modelo quase-geoidal foi realizado por integração numérica através da Transformada Rápida de Fourier (FFT). A anomalia de gravidade de Molodensky foi determinada em uma grade 5' e reduzida e restaurada usando a técnica Residual Terrain Model (RTM) e o MGG XGM2019e com ordem e grau 250 e 720. O modelo geoidal foi derivado das anomalias de Bouguer. A validação do modelo quase-geoidal apresentou Root Mean Square (RMS) da diferença de $18 \mathrm{~cm}$ comparado às medidas Global Positioning System (GPS) na rede de nivelamento.

Keywords: Altitude; Geoide; Quase-geoide; estado de São Paulo.

\section{Introduction}

From a physical point of view, the Earth is described by the geoid which is an equipotential surface of the gravity field, best approximated in nature by the mean sea level. Due to the rotational effect and the non-homogeneous mass distribution, the geoid has irregularities, described by the difference between the surface of the global reference ellipsoid, currently the Geodetic Reference System 1980 (Moritz 2000), and the geoid surface itself. In terms of shape, the separation between these surfaces is called geoid undulation or geoid height $(N)$. Regarding heights, $N=h-H$ is the difference between the geodetic height $(h)$, associated with the ellipsoidal surface, and the orthometric height $(H)$, associated with the geoid.

The main difficulty in estimating the geoid model is to reduce the observations taken at the physical surface to the surface of the geoid. Alternatively, the quasigeoid model can be used. In this case, the vertical coordinate is the normal height $\left(H_{N}\right)$ and the association with geometrical quantities is provided by the height anomaly $(\zeta)$.

In its 2018 realization, the Brazilian Vertical Reference Frame (BVRF), referred to Imbituba and Santana tide gauges, adopted the normal height system (Luz 2016, IBGE 2019). However, the official geoid model in the country is still MAPGEO2015 (Blitzkow et al. 2016). The previous realization of BVRF was based on normal-orthometric heights, coming from a readjustment of the network carried out in 2011. Studies of Ferreira, De Freitas, and Heck 2011, Severo et al. (2013), and Yakubu, Agyei, and Ferreira (2019) have shown the heights derived from 2011 BVRF are closer to normal height. Whereas in São Paulo state, considerable corrections were applied to the normal-orthometric system, ranging about -28 and $13 \mathrm{~mm}$ (Albarici et al. 2019). The Global Positioning Systems (GPS) determinations on the levelling network had a discrepancy, in terms of Root Mean Square (RMS) difference, of $\pm 17 \mathrm{~cm}$ between this realization and the MAPGEO2015. Currently, the BVRF discrepancy with MAPGEO2015 is around $30 \mathrm{~cm}$.

An accurate Digital Terrain Model (DTM), adequate terrestrial and airborne gravimetric data, combined with information from Global Geopotential Models (GGMs), are fundamental for the 
production of geoid and quasigeoid models with high-resolution. The computation task is based on the solution of a Geodetic Boundary Value Problem (GBVP). Its resolution is related to the height concepts, which should be analyzed from the physical and geometric perspectives, considering the reference surface of altimetric measurements and interpreting its meaning as the reference surface of the gravity field (Blitzkow, Campos, and De Freitas 2004).

The geoid and quasigeoid models are auxiliary tools for the altimetric system since they provide $N$ and $\zeta$, respectively, enabling the conversion between heights of geometric meaning into physical quantities. However, the quasigeoid is not an equipotential surface, therefore, it differs conceptually from the geoid. Due to the mathematical and physical concepts involved, for compatibility purposes, it is recommended that the system of normal height uses a quasigeoid model. In this sense and considering the present scenario, in which MAPGEO2015 has a $30 \mathrm{~cm}$ of RMS difference with the BVFR, a quasi geoid model is most suitable because it is closer to the normal heights system. This paper aimed to estimate the geoid and quasigeoid models for the São Paulo state using the normal height from the 2018 BVRF and the updated gravimetric data (Silva et al. 2020). An analysis has been made comparing the normal heights which are given for the levelling network points.

\section{Quasigeoid Estimation}

The quasigeoid determination is based on the solution of an oblique GBVP (Heck 1989). According to the Molodensky approach, the GBVP is solved using the physical surface as a boundary, considering the Earth gravity potential there equal to the gravity potential on the level ellipsoid $\left(W_{P}=U_{Q}\right)$, with the points $P$ and $Q$ located along the same normal to the ellipsoidal surface (Hofmann-Wellenhof and Moritz 2006). In this approach, the surface of the telluroid is used as a boundary reference (Figure 1).

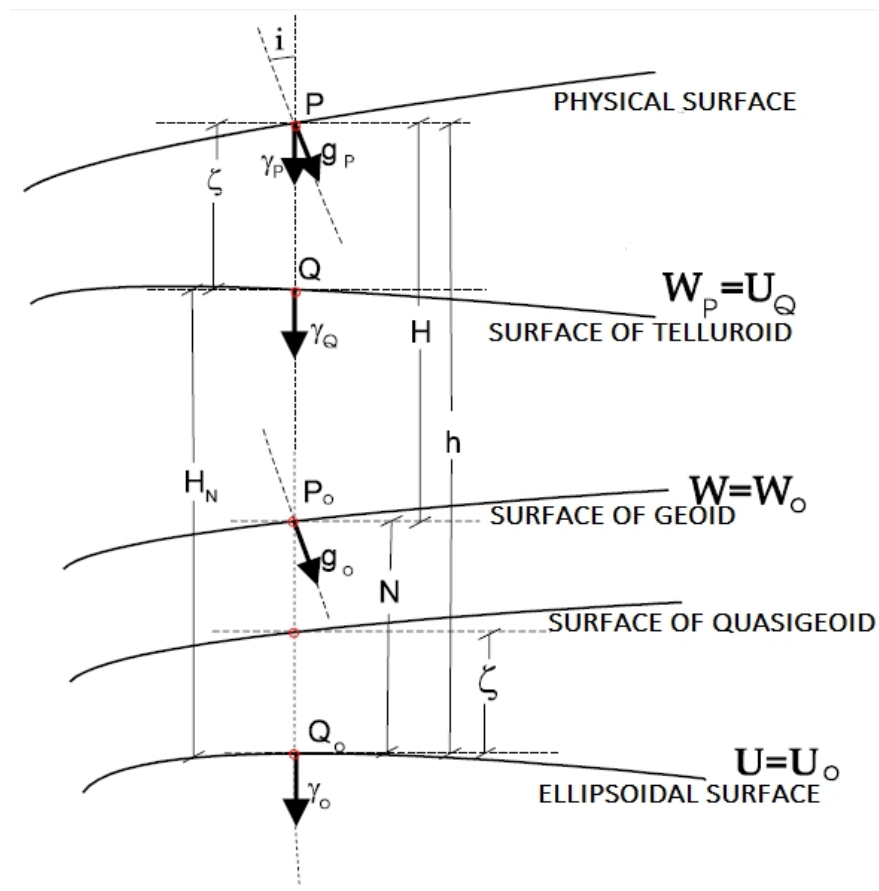

Figure 1: Geometric representation of the height system elements. 
Source: Adapted from Blitzkow, Campos, and De Freitas (2004).

The distance between the telluroid and physical surfaces along the geodetic normal is denoted as $\zeta$. On the other hand, representing $\zeta$ along the normal over the ellipsoidal surface, it gives rise to another reference surface, named quasigeoid, characterized by being a non-equipotential surface considerably close to the geoid surface (Hofmann-Wellenhof and Moritz 2006).

In the quasigeoid computation, based on the Molodensky formulation (Molodensky, Yeremeyev, and Yurkina 1962) for a solution of an oblique problem, the height anomaly $(\zeta)$ at a point $P$ is determined by Stoke's kernel (Hofmann-Wellenhof and Moritz 2006):

$$
\zeta(P)=\frac{R}{4 \pi \gamma_{Q}} \iint\left(\Delta g_{M O}+g_{1}\right) S(\psi) d \sigma
$$

where $R$ is the mean Earth radius; $\gamma_{Q}$ is the normal gravity acceleration at the latitude of $Q ; \Delta g_{M O}$ is the Molodensky gravity anomaly; $g_{1}$ is the correction of the Molodensky term; $S(\psi)$ is the Stokes kernel and $\sigma$ the unit sphere. According to Yildiz et al. (2012) applying the Residual Terrain Model (RTM) reduction (Forsberg 1984), the $g_{1}$ term becomes insignificant. On the other hand, in the theory view for an accurate geoid, it is necessary a rigorous formulation because the terrain corrections are closer to the zeroth-order approximation (Ferreira and De Freitas 2010). In the BVRF 2018 context and for a 5' geoid resolution, it was considered acceptable.

The RTM technique, used to replace the $g_{1}$ term, involves the computation of the high-frequency component of the topographic effect on the gravity field. These short wavelength constituents are quantified from a Digital Terrain Model (DTM) of the mean elevations generated by a low-pass filter. It is executed by a moving average operator, corresponding to the distance in which the heights will be averaged (Forsberg 1997). The determination of this surface, also called the reference DTM or RTM-surface, is produced usually using DTM of high resolution, representing the real topography of the Earth.

The attraction potential of the topographic masses $\left(\Delta g_{R T M}\right)$, expression (2), is computed on the physical surface (PS), in the z-direction with the approximation of a rectangular prism (Mader 1951, Nagy 1966), considering $2.67 \mathrm{gcm}^{-3}$ for the mass density $(\rho)$ of topographical features on the continent and $1.030 \mathrm{gcm}^{-3}$ for oceanic topography (Tziavos and Sideris 2013).

$$
\Delta g_{R T M}=2 \pi G \rho\left(H-H_{\text {ref }}\right)-K \iint_{P S} \int_{H_{\text {ref }}}^{H} \rho \frac{H_{N}-z}{l^{3}} d x d y d z
$$

where, $H_{\text {ref }}$ is the height of the reference DTM; $H$ the height of the topographic masses defined by the high-resolution DTM; $G$ is Newton's gravitational constant; $H_{N}$ is the normal height of the point; / is the distance between $P$ and running integration point $Q$, and $d x d y d z$ is the differential volume element. The first term is the difference of two Bouguer plates with different thickness. The thickness of the first one is realized by the height of the computation point and that of the second plate by the height of the reference surface. This scheme implies that the masses above the geoid are first removed by the complete Bouguer reduction and then are restored with the reference Bouguer plate (Tziavos and Sideris 2013). 
In the remove-restore process, the RTM is considered to remove the high frequencies of the Molodensky gravity anomaly and to restore similar frequencies in the height anomaly. It is important to consider the compatibility between the GGM degree and order and smoothness of the RTM reference surface, to properly reduce the topographic effects because the GGM has also a DTM contribution.

\section{Input data set and pre-processing}

The boundary data used to solve the GBVP, with the Molodensky approach, is Molodensky's gravity anomaly $\left(\Delta g_{M O}\right)$, defined in (3) (Hofmann-Wellenhof and Moritz 2006).

$$
\Delta g_{M O}=g_{P}-\gamma_{Q}
$$

with the gravity acceleration $\left(g_{p}\right)$ observed at point $P$ on the physical surface of the Earth and the normal gravity acceleration $\left(\gamma_{Q}\right)$ evaluated by (4) at point $Q$ on the surface of the telluroid, according to expression (4) (Hofmann-Wellenhof and Moritz 2006).

$$
\gamma_{Q}=\gamma_{Q_{0}}\left[1-2\left(1+f+m-2 f \sin ^{2} \varphi\right) \frac{H_{N}}{a}+3\left(\frac{H_{N}}{a}\right)^{2}\right]
$$

where $\gamma_{Q_{0}}$ corresponds to the normal gravity acceleration value on the ellipsoidal surface, $H_{N}$ is the normal height, the parameters associated with the reference ellipsoid ( $f$ is the flattening, $a$ major semi-axis), $m$ is a unitless physical constant equivalent to 0.00344978600308 (Moritz 2000), and $\varphi$ is latitude.

The gravimetric survey from the Escola Politécnica, Universidade de São Paulo (EPUSP) database (continental data in Figure 3), was analyzed and reprocessed using GRAVSUR software (Amarante 2012) and the DIVA software, developed by Bureau Gravimétrique International (BGI), see Silva et al. 2020. The geodetic height was measured by dual-frequency GPS receivers in seventeen percent of the gravimetric surveys. The gravity densification points without geodetic height information (82.5 \%) were obtained using XGM2019e geoid height (truncated with degree and order: 2190) and orthometric height by expression (5). Concerning these latest data, it was not possible to determine the $0.50 \%$ orthometric height measurement technique. The IBGE benchmarks inform the normal height, and the other data was obtained by expression (6) using the functional height_anomaly_ell by ICGEM site, sometimes called "generalized pseudo-height-anomaly"( $\left.\zeta_{e}\right)$. It is equal to the geoid over the sea. The height anomaly at the given longitude and latitude is approximated by Bruns' formula (Barthelmes 2013, Ince et al. 2019). The absolute difference between height anomaly ( $H_{N}$ informed or computed) and pseudo-height-anomaly was shown in Table 1 and Figure 2.

$$
\begin{aligned}
& H=h-N \\
& H_{N}=h-\zeta_{e}
\end{aligned}
$$

Table 1: Statistics of height anomaly difference (mGal). 


\begin{tabular}{l|c|c|c|c|c}
\hline Statistics & Min & Max & Mean & SD & RMS \\
\hline$\left|\zeta-\zeta_{e}\right|$ & 0.00 & 0.08 & 0.01 & 0.01 & 0.02 \\
\hline
\end{tabular}

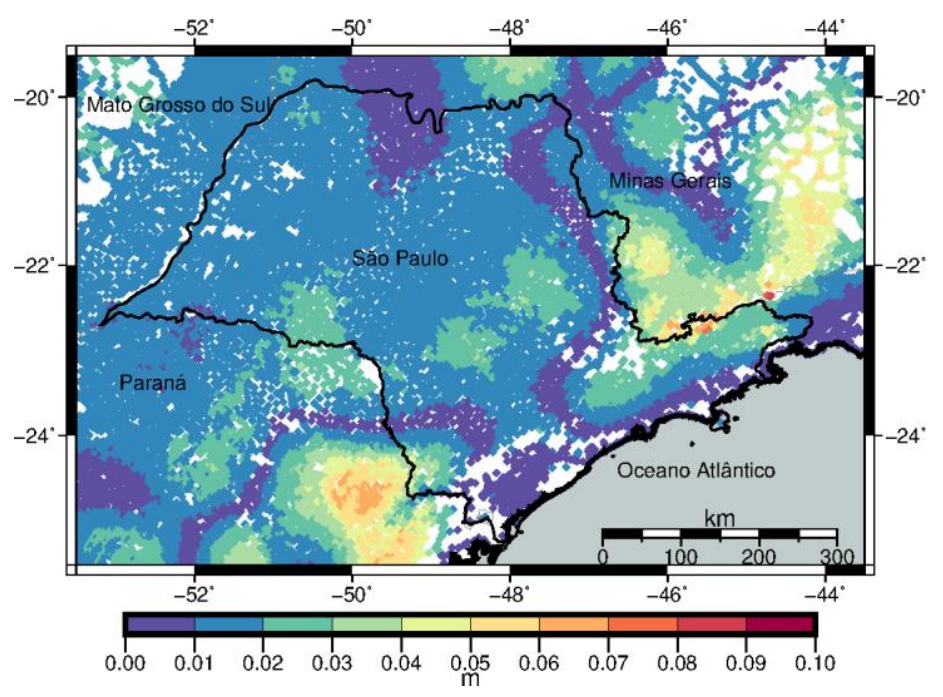

Figure 2: Height anomalies difference.

The gravity atmospheric correction $\left(\delta g^{a t m}\right)$ (7) was also included to the computation (Wenzel 1985).

$$
\delta g^{a t m}=0.874[\mathrm{mGal}]-9.9 \times 10^{-5}[\mathrm{mGal} / \mathrm{m}] H_{N}+3.5625 \times 10^{-9}\left[\mathrm{mGal} / \mathrm{m}^{2}\right] H_{N}^{2}
$$

The data used covering the region of the state of São Paulo and $2^{\circ}$ beyond its borders, totaling 50432 terrestrial gravimetric points. Figure 3 shows the distribution of the data and the DTU (Andersen et al. 2014) gravity anomalies in the ocean area. The $\Delta g_{\text {мо }}$ values range between -83.76 and $133.58 \mathrm{mGal}$ (Table 2).

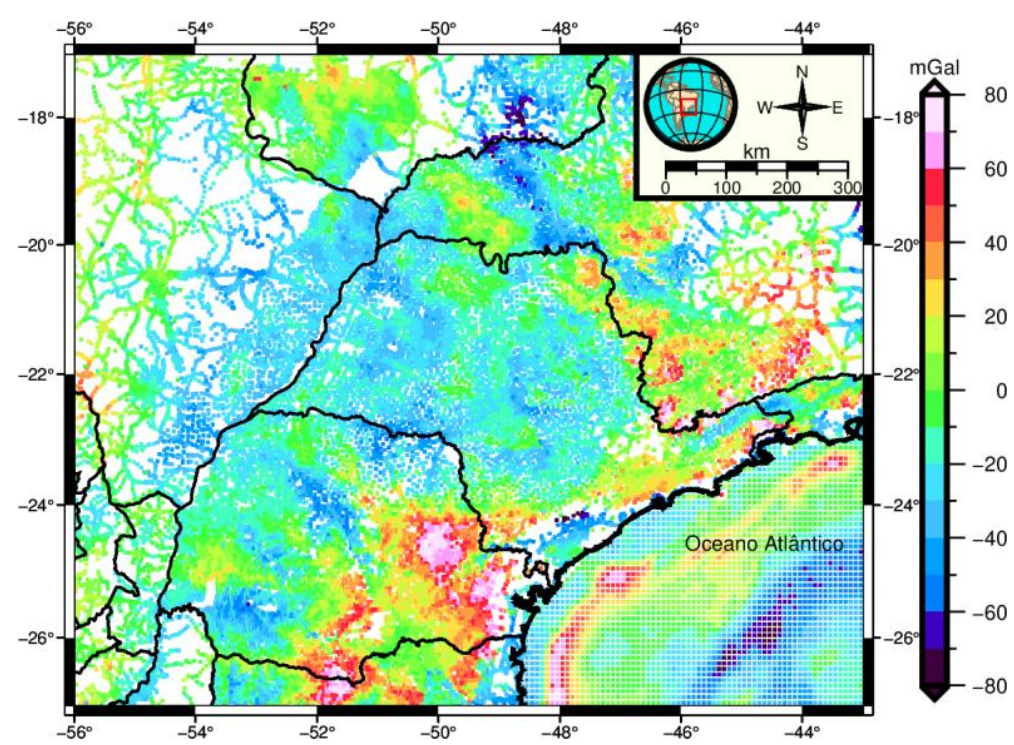

Figure 3: Molodensky gravity anomalies. 
Table 2: Statistics of Molodensky gravity anomaly (mGal).

\begin{tabular}{c|c|c|c|c|c}
\hline Statistics & Min & Max & Mean & SD & RMS \\
\hline$\Delta g_{\text {мо }}$ & -83.76 & 133.58 & -3.87 & 26.13 & 26.14 \\
\hline
\end{tabular}

The determination of the geoid and quasigeoid models requires a distribution of gravimetric data over an extension on the order of 100/200 km outside the area of interest. To cover the areas of gravimetric voids in the states surrounding São Paulo, the Molodensky gravity anomaly of the GGM XGM2019e was truncated to degree and order maximum (nmax) of 2190, complemented with the topographic effects of the terrain, determined by the RTM technique (8).

$$
\Delta g_{M O}^{\text {voids }}=\Delta g_{M O}^{G G M}+\Delta g_{M O}^{R T M}
$$

The DTM, SRTM15 + with a resolution of 15", was the model chosen for the application of the RTM technique due to its availability for the area of the continent and the ocean. It is derived from the Shuttle Radar Topography Mission (SRTM), executed by the former National Imagery and Mapping Agency, now the National Geospatial-Intelligence Agency, and the National Aeronautics and Space Administration (Farr et al. 2008). The SRTM data was complemented with the mission data of Advanced Spaceborne Thermal Emission and Reflection Radiometer. In the ocean, this model has data from the missions CryoSat-2 and Jason-1 (Tozer et al. 2019).

For the ocean area, gravity anomalies of the DTU13 model with a resolution of 1 ' were used. This ocean model was produced from ten different satellites: TOPEX/POSEIDON, Jason-1, Jason-2, Geosat, ICESat, ERS-1 and 2, ENVISAT, Cryosat-2, and GOCE (Andersen et al. 2014).

The anomalous field elements of the GGMs were calculated on the International Center for Global Gravity Field Models Services (Ince et al. 2019), with the parameters of the GRS80 ellipsoid, and the zero tide system (due to the IAG recommendations and for compatibility with the tide system of the used variables), and without the zero degree term (IAG 2015).

\section{Methodology and Results}

\subsection{Quasigeoid model}

The Experimental Gravity Field Model (XGM2019e Zingerle et al. 2020) was chosen due to the consistency of the model with the GPS determinations on the levelling network, having RMS difference of approximately $30 \mathrm{~cm}$ for the state of São Paulo (Gruber et al. 2019). This model was combined with satellite data from the GOCO06S model (Kvas et al. 2021) and terrestrial gravimetric measurements. The topography of the continent is derived from the EARTH2014 model (Hirt and Rexer 2015) and the ocean from the DTU13 model. Its coefficients in the series of spherical harmonic functions reach the degree and order 5399, with a spatial resolution of $4 \mathrm{~km}$ (Zingerle et al. 2020).

The RTM computation has been carried out using the three DTM with a high, a mean, and a lowresolution. The latter DTM, gridded in 3', was produced in the SELECT program, developed by (Forsberg and Tcherning 2008), using the high-resolution DTM, SRTM15+. The mean-resolution 
DTM, named reference surface, had been generated with the TCGRID program (Forsberg and Tcherning 2008), using the low-resolution DTM and SRTM15+ model.

The contribution of RTM to increase the high frequencies of $\Delta g_{M O}^{\text {voids }}$ and the relationship between normal height and Molodensky gravity anomaly is shown in Figure 4.
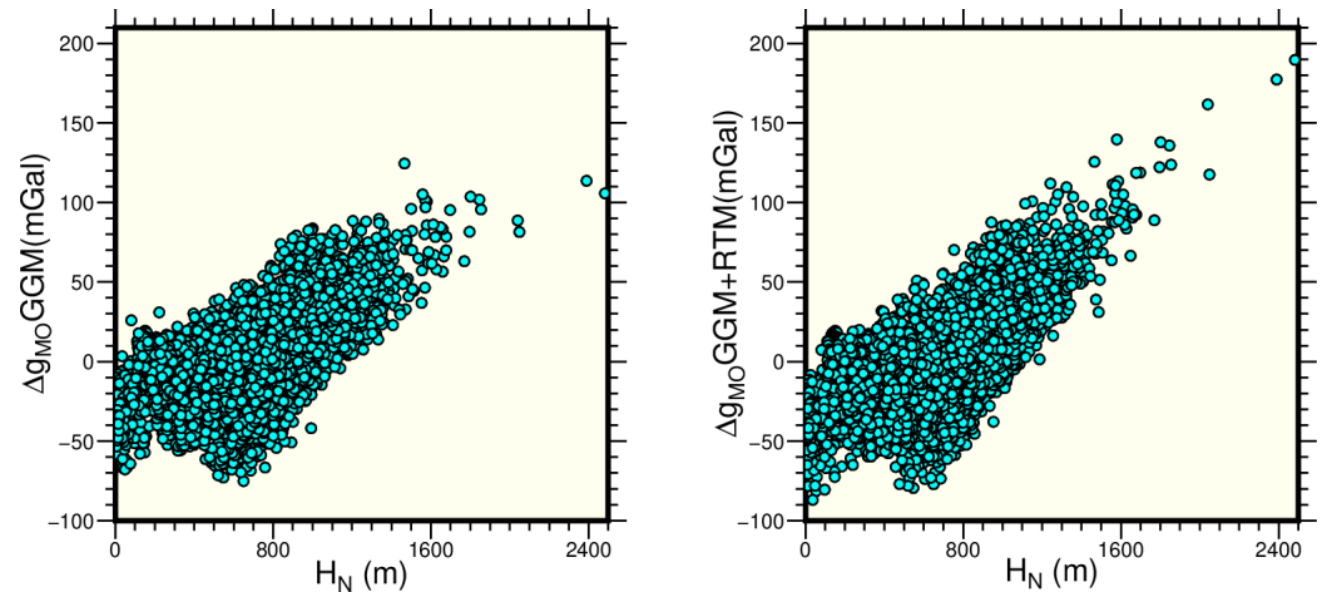

Figure 4: Molodensky gravity anomaly and normal heights.

Commonly, in regions with in situ gravimetric data, it is sufficient to use only the low frequencies derived from a GGM. For example, a study by Vu, Bruinsma, and Bonvalot (2019) determined a quasigeoid model for Vietnam, applying the methodology of the present work, removing and restoring with the long and medium wavelengths, using nmax=720. In São Paulo state the RMS difference between XGM2019e nmax=250 and 720 and the GPS/levelling is about $17 \mathrm{~cm}$ and 16 $\mathrm{cm}$ respectively (Gruber, Zingerle, Pail, et al. 2019). Based on these differences, to evaluate the discrepancy of the quasigeoid model, employing different degree and order, two approaches were adopted: the use of long wavelengths of the gravity anomaly, derived from the XGM2019e model with $n \max =250$, and the long and medium wavelengths of the XGM2019e with nmax $=720$.

The $\Delta g_{M O}$ wavelengths were separated according to the expression (9), for each degree and order mentioned. For this purpose, references DTMs were computed choosing a factor according to the nmax used and its spatial resolution to obtain an optimal smoothing for the RTM. The MDTREF-RTM routine, developed by EPUSP, was used to determine this suitable factor (Table 3) for the reference surface, basing on the smallest RMS for each nmax of $\Delta g_{M O}^{R E S}$.

Table 3: Optimus resolutions factor for the reference DTM.

\begin{tabular}{c|c|c|c|c|c}
\hline nmax & Factor & Minutes & Degree & $\mathrm{Km}$ & $\mathrm{RMS}$ (mGal) \\
\hline 250 & 9 & 27 & 0.45 & 50.0 & 8.08 \\
\hline 720 & 3 & 0 & 0.15 & 16.7 & 6.99 \\
\hline 2190 & 1 & 3 & 0.05 & 5.6 & 7.41 \\
\hline
\end{tabular}

$$
\Delta g_{M O}^{R E S}=\Delta g_{M O}-\Delta g_{M O}^{G G M}-\Delta g_{M O}^{R T M}
$$

The residual Molodensky anomaly anomalies, defined in (9), were interpolated in a $5^{\prime}$ grid with the GEOGRID software (Forsberg and Tcherning 2008), through the least-squares collocation technique. A minimum amount of 5 points had been assigned to perform the interpolation. The 
program provides as an output file a grid with the $\Delta g_{M O}^{\text {RES }}$ values and another file with the standard deviation. Two grids were generated by removing the long wavelengths with nmax $=250$ (Figure 5) and $n \max =720$ (Figure 6).
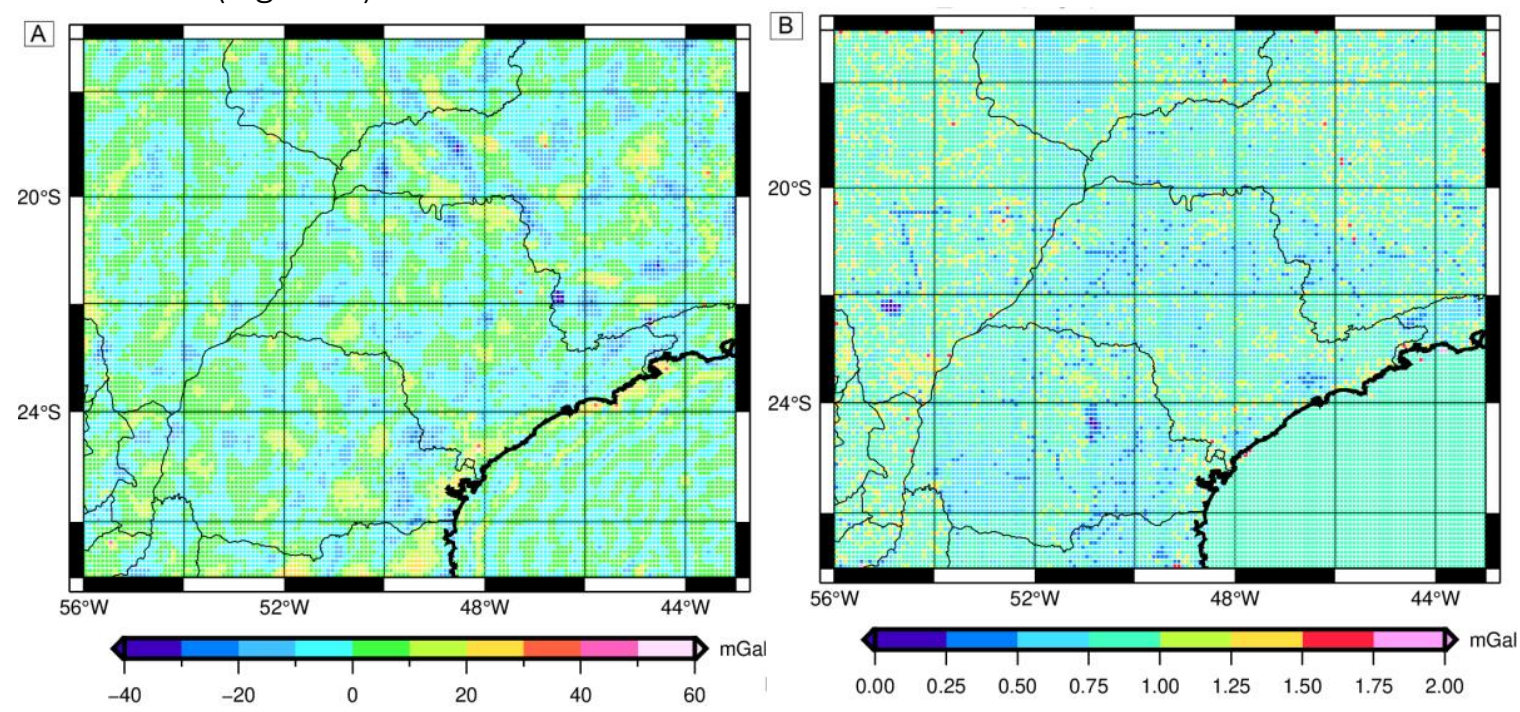

Figure 5: Molodensky residual gravity anomaly based on RTM and XGM2019e nmax= 250 (A: grid 5’x5'; B: Collocation errors).
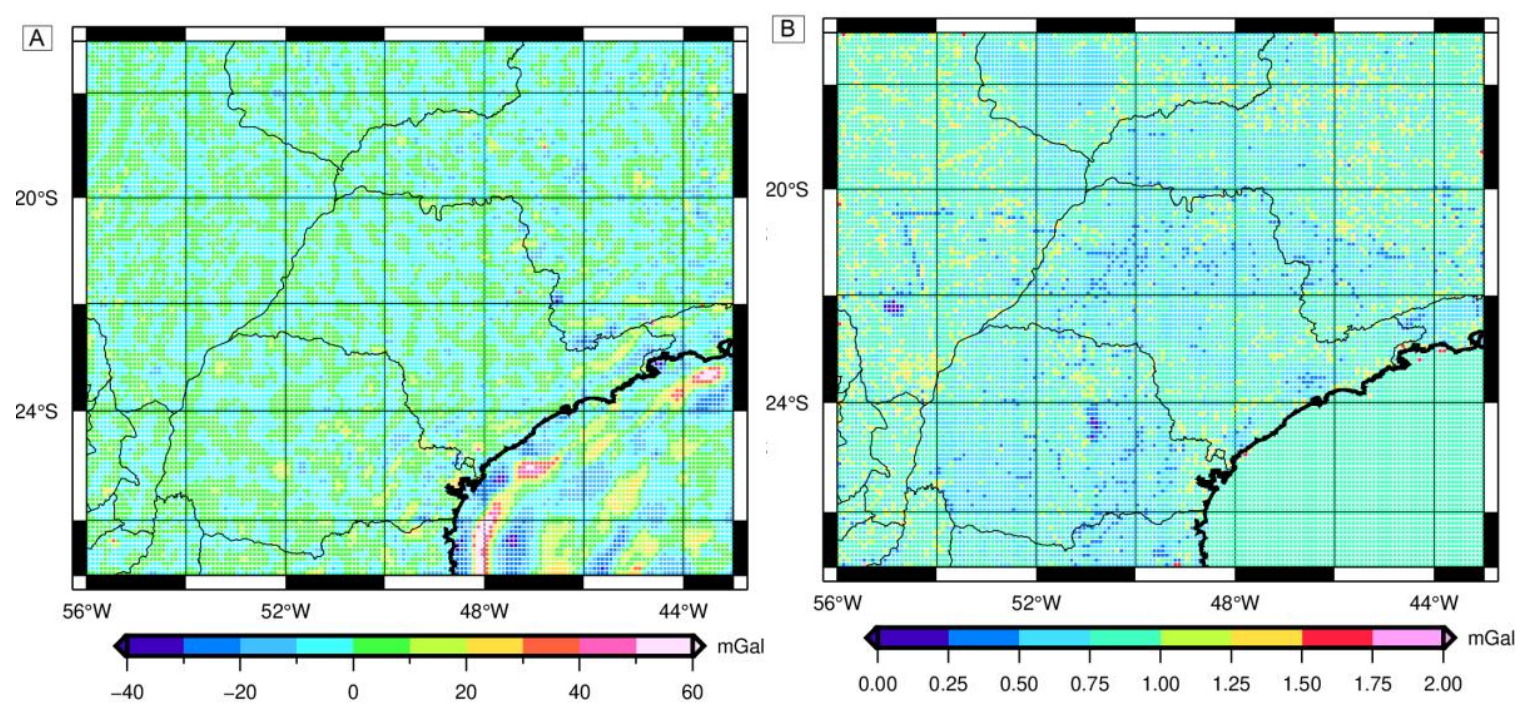

Figure 6: Molodensky residual gravity anomaly based on RTM and XGM2019e nmax= 720 (A: grid 5’x5'; B: Collocation errors).

The numerical integration of expression (9), was performed by Fast Fourier Transform with the modified Stokes kernel (Wong and Gore 1969) using the SPFOUR program (Forsberg and Tcherning 2008). As an output, the routine provided the residual height anomaly, which was restored in expression (10), with the contribution of the elements previously removed:

$$
\zeta_{P}=\zeta_{G G M}+\zeta_{R E S}+\zeta_{R T M}
$$

To restore the gridded height anomaly, height values were interpolated using the SRTM15+. The effects of the RTM on the height anomaly have been computed using the DTMs of the removal step, with the TC program (Forsberg and Tcherning 2008). Similarly to the removal step, the restoration of long wavelengths was performed with the height anomaly of the model XGM2019e 
with $n \max =250$ and $n \max =720$. The final height anomaly computation was assigned a value of $0.93 \mathrm{~m}$ for the zero-order term to match to the local reference system. The executed process is shown in Figure 7.

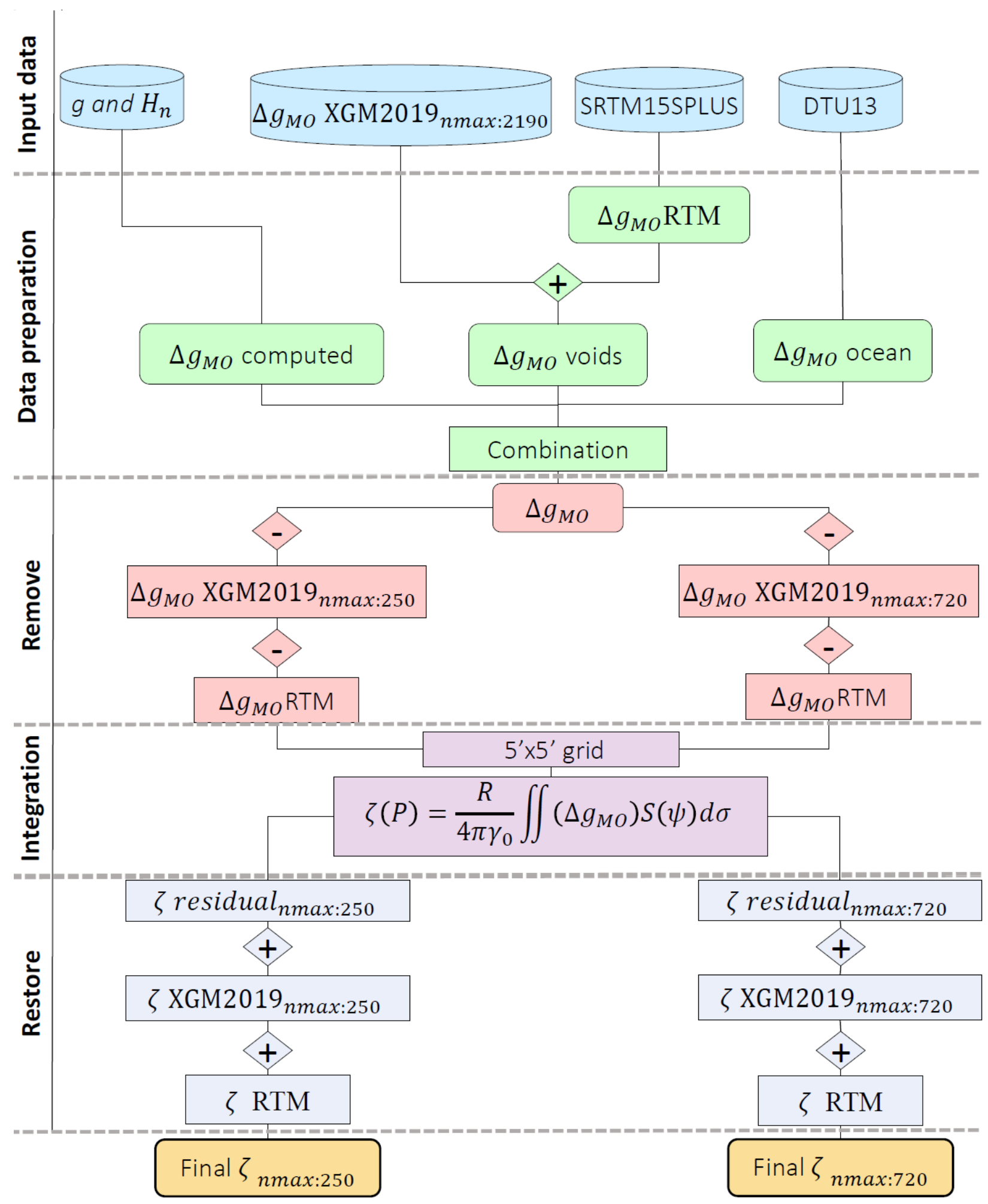

Figure 7: Flowchart of quasigeoid model computation. 
The quasigeoid models determined with the XGM2019e with nmax $=250$ and nmax $=720$ are shown in Figure 8.
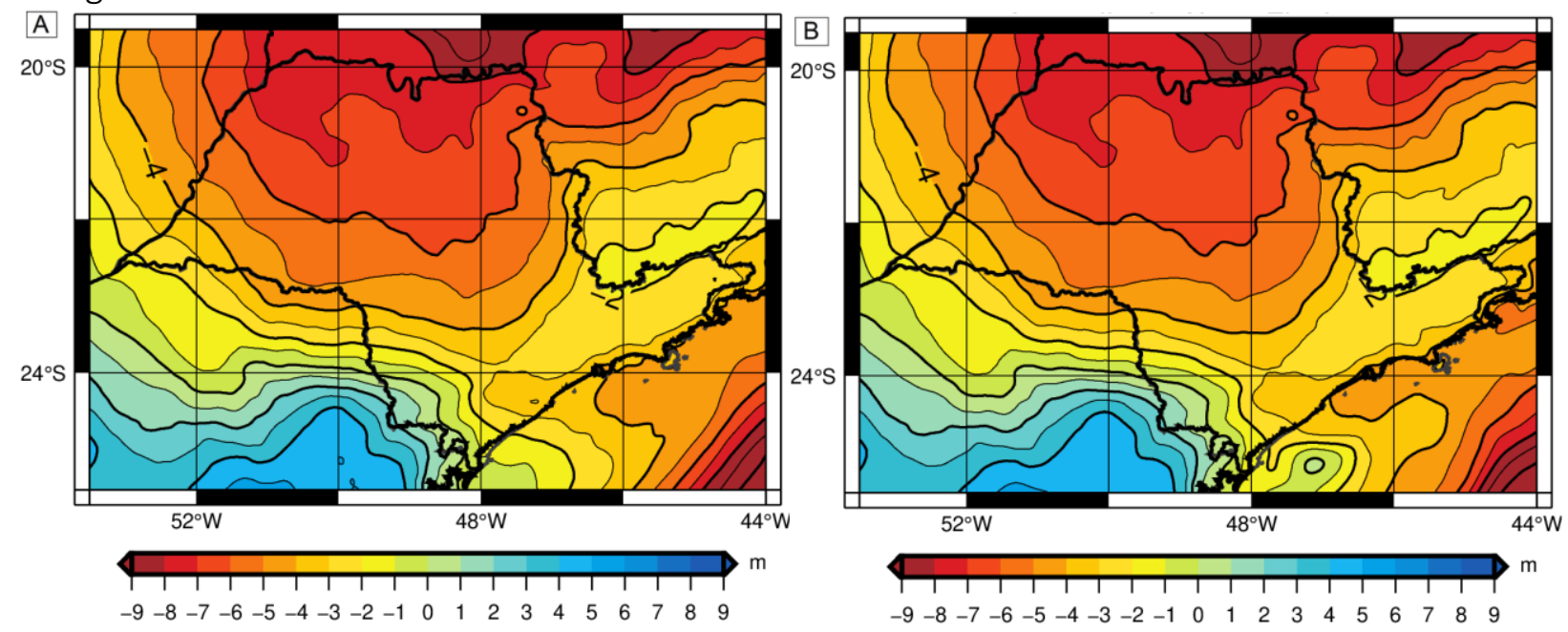

Figure 8: Quasigeoid model for São Paulo (A-nmax= 250; B-nmax= 720).

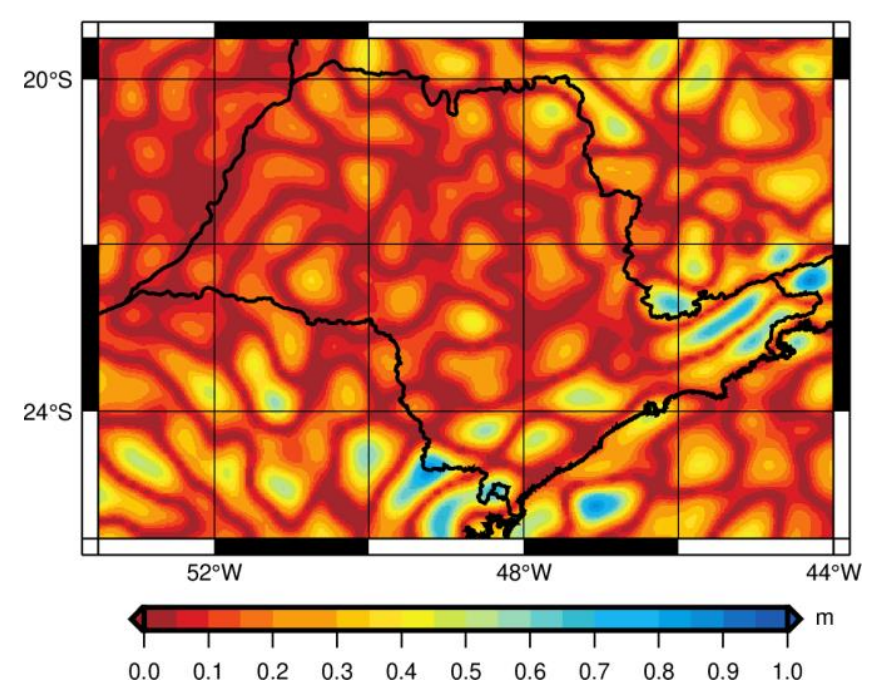

Figure 9: Absolute difference between quasigeoid models with $n \max =250$ and $n \max =720$.

Table 4: Statistics of quasigeoid difference between nmax $=250$ e $720(\mathrm{~m})$.

\begin{tabular}{c|c|c|c|c|c}
\hline Statistics & Min & Max & Mean & SD & RMS \\
\hline$\left|\zeta_{\text {max }=250}-\zeta_{\text {nmax }=720}\right|$ & 0.00 & 1.02 & 0.15 & 0.13 & 0.21 \\
\hline
\end{tabular}

The $n \max =250$ and $n \max =720$ solutions are significantly similar for the continent due to the homogeneous distribution of gravimetric data in the area. In the ocean region and close to the coast the discrepancies can reach $1.02 \mathrm{~m}$ (Figure 9 and Table 4), demonstrating a poor representation of the GGMs in those areas. This occurs because the high-resolution modeling of coastal regions requires gravimetry and the measurement of phenomena such as temperature, salinity, speed of currents, among other factors characterizing the Sea Surface Topography (Santana and Dalazoana 2020). 


\subsection{Geoid model}

The conversion of the quasigeoid to the geoid surface involved the application of the Bouguer anomaly and height values. The relationships between normal height and height anomaly, and orthometric height and height undulation, are given, respectively, by the expressions (6) and (5), according to (11).

$$
N-\zeta=H_{N}-H
$$

The heights definition in terms of geopotential numbers with the respective gravimetric reductions are given according to the expressions (12) and (13) (Forsberg 1997).

$$
\begin{aligned}
& H=\frac{C}{\bar{g}}=\frac{C}{g_{P}+0.0424\left[\mathrm{mGal} \cdot \mathrm{m}^{-1}\right] H} \\
& H_{N}=\frac{C}{\gamma}=\frac{\mathrm{C}}{\gamma_{0}-0.1543\left[\mathrm{mGal} \cdot \mathrm{m}^{-1}\right] H_{N}}
\end{aligned}
$$

Rewriting the difference between the height anomaly and the geoid undulation over the same denominator results in:

$$
N-\zeta=H_{N}-H \cong \frac{g_{P}-\gamma_{0}+0.1967\left[\mathrm{mGal} \cdot \mathrm{m}^{-1}\right] H}{\gamma_{0}} H=\frac{\Delta g_{B}}{\gamma_{0}} H
$$

The expression (14) shows the correction applied to the height anomaly suited to obtain an idea of the geoid magnitude (Hofmann-Wellenhof and Moritz 2006). This computation was performed using N2ZETA program (Forsberg and Tcherning 2008), with Bouguer anomalies derived from XGM2019e GGM with nmax=2190. The height defined by $H$ corresponds to the classic orthometric height whose value can be given by SRTM15+. The routine generates the geoid undulations using the height anomaly determined in the section 4.1, the SRTM height, and the Bouguer anomaly. The geoid model, produced from the quasigeoid, is shown in Figure 10.
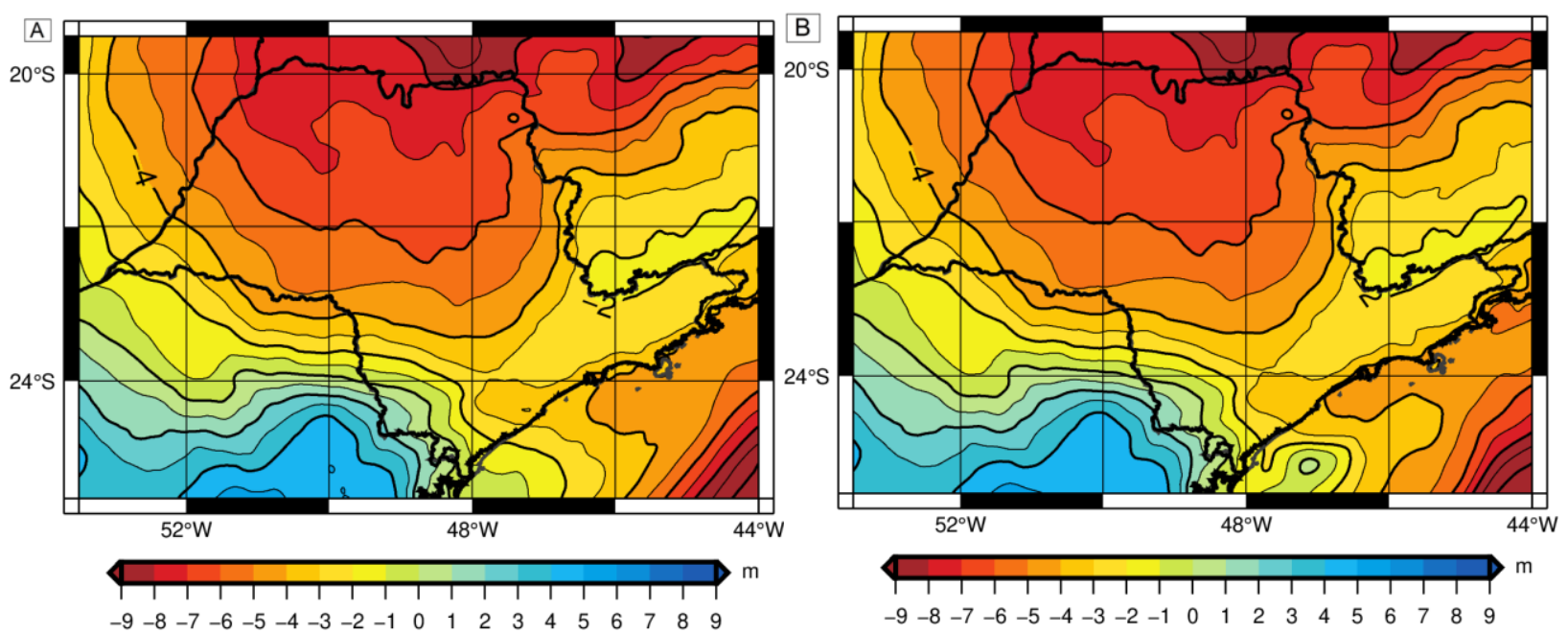

Figure 10: Geoid model from São Paulo (A-nmax= 250; B-nmax= 720). 


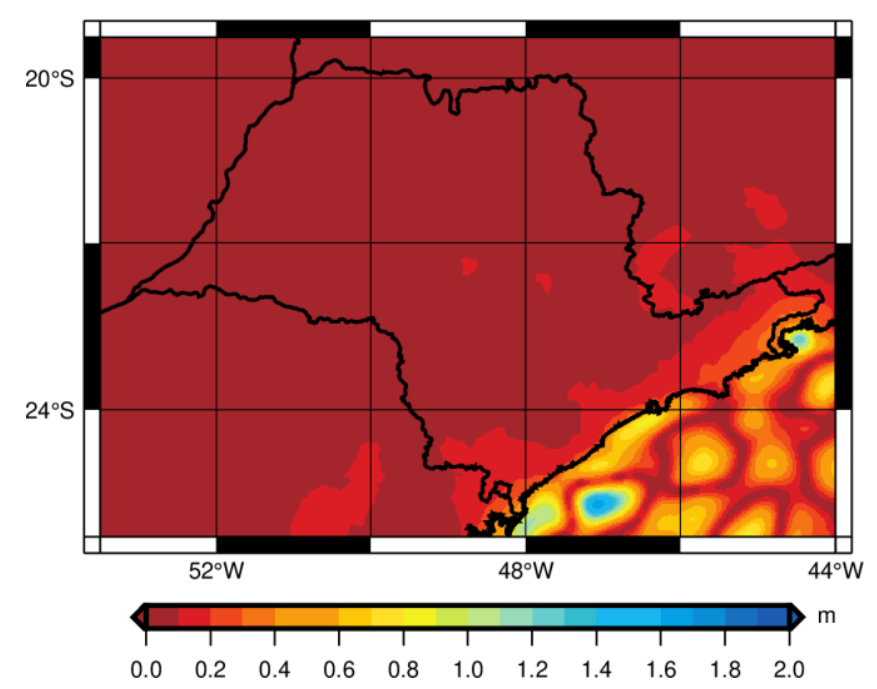

Figure 11: Absolute difference between geoid models with nmax $=250$ and 720 .

Table 5- Statistics of geoid difference between nmax=250 e $720(\mathrm{~m})$.

\begin{tabular}{l|c|c|c|c|c}
\hline Statistics & Min & Max & Mean & SD & RMS \\
\hline $\mid N_{\text {nmax }=250}-N_{\text {nmax }}$ 720 & 0.00 & 2.07 & 0.10 & 0.18 & 0.21 \\
\hline
\end{tabular}

The use of Bouguer anomalies with nmax $=2190$ reduced the continental discrepancies between nmax $=250$ e 720 (Figure 11 and Table 5), showed in the quasigeoid solutions (Figure 9 and Table 4 ), and increase the differences in the ocean. Since the quasigeoid and geoid surfaces differ in less than $30 \mathrm{~cm}$, the iso-lines illustrated in metric units, are similar between the models. In the ocean region, actually, they are identical. The difference between the surfaces is shown in Figure 12. The quasigeoid and geoid surfaces have absolute maximum discrepancies of $21 \mathrm{~cm}$ in the region. Similar differences are shown by Albarici et al. (2018) in São Paulo comparing normal and orthometric heights. The mean absolute difference between the solutions is $4 \mathrm{~cm}$ for both degree and order (Table 6).

Table 6: Statistics of the separation geoid and quasigeoid (mGal).

\begin{tabular}{l|l|l|l|l|l}
\hline Statistics & Min & Max & Mean & SD & RMS \\
\hline$|\zeta-N|_{n \max =250}$ & 0.00 & 0.21 & 0.04 & 0.03 & 0.05 \\
\hline$|\zeta-N|_{n \max =720}$ & 0.00 & 0.21 & 0.04 & 0.03 & 0.05 \\
\hline
\end{tabular}



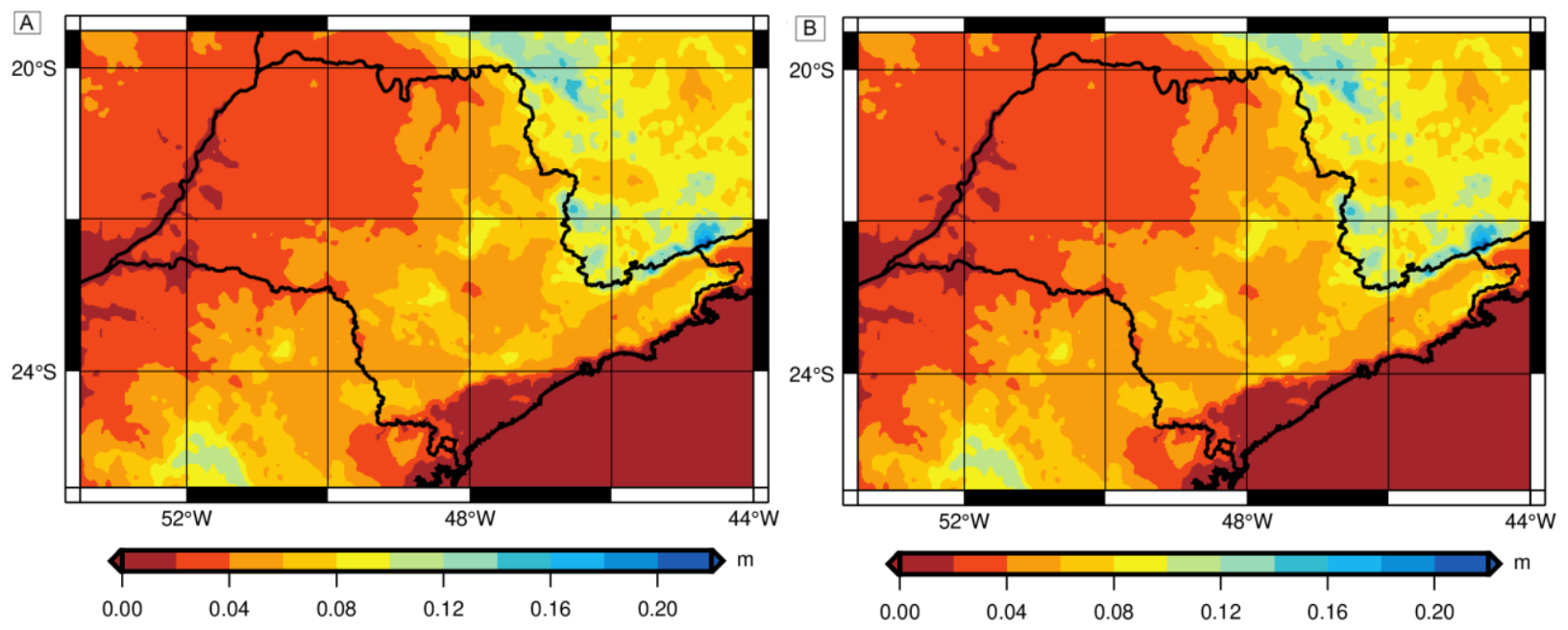

Figure 12: Difference between the geoid and quasigeoid model $(A-n m a x=250 ; B-n m a x=720)$.

\section{Validation of the quasigeoid model with GPS on the levelling points}

The validation of the geoid and quasigeoid models is performed by evaluating the consistency of the geoid undulation or the height anomaly with the values derived from the geodetic height in conjunction with the height adopted in the local vertical system. In Brazil, normal heights enable the evaluation of the quasigeoid model due to its compatibility with the height anomaly. The geoid was not tested due to orthometric height unavailability. As all GPS/levelling control points are located on the continent, the oceanic part also could not be evaluated.

For the mentioned model evaluation, 291 GPS determinations on the levelling network were used, distributed in an area of $1^{\circ}$ smaller than the region used in the computation. Models with $n \max =250$ and $n \max =720$ were evaluated separately. Table 7 shows the statistics of the residuals.

Table 7: GPS/levelling evaluation with 291 points (values in meters).

\begin{tabular}{l|c|c|c|c}
\hline$n \max$ & Min & Max & Mean & SD \\
\hline 250 & -0.78 & 0.36 & -0.33 & 0.18 \\
\hline 720 & -0.88 & 0.37 & -0.40 & 0.18 \\
\hline
\end{tabular}

The standard deviations of the models, produced with the XGM2019e with nmax $=250$ and $n \max =$ 720 , indicate that there is consistency between the two solutions. The absolute mean presented by the XGM2019e nmax $=250$ model shows a smaller value, compared to nmax $=720$. Figure 13 illustrates the behavior of the model according to benchmarks in the São Paulo region. 


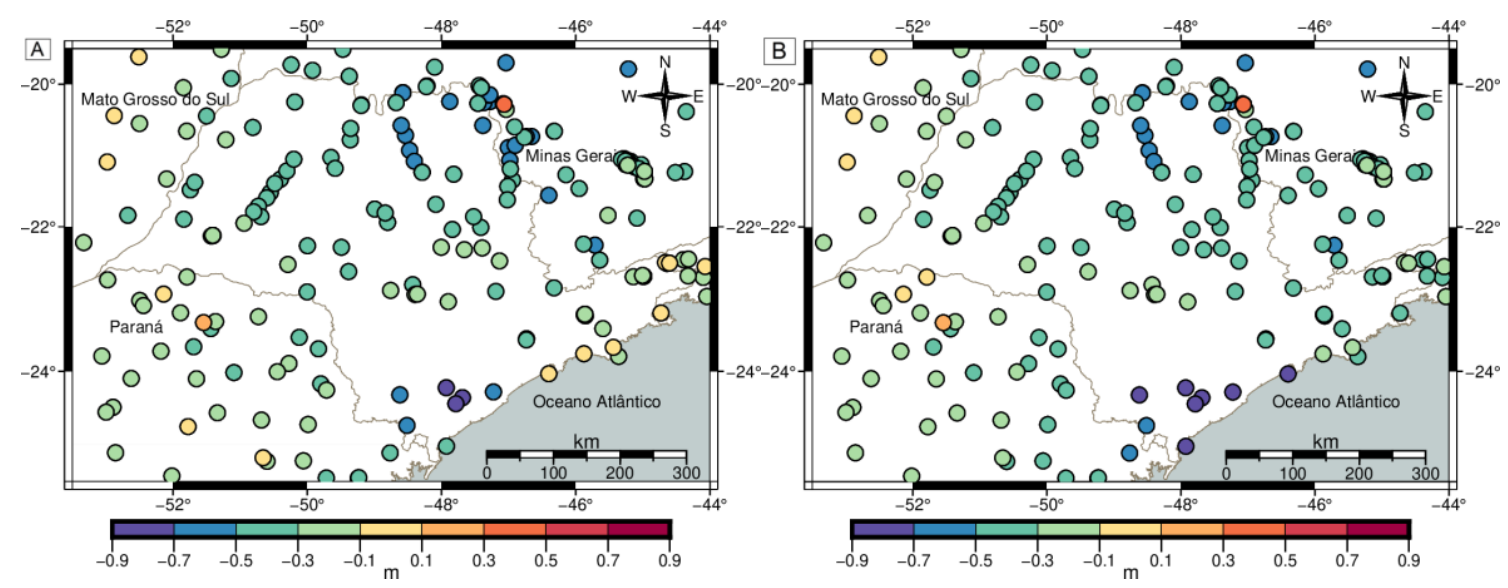

Figure 13: GPS/levelling evaluation with 291 points (A-nmax= 250; B:nmax= 720).

Figure 13 indicates that the model produced with $n \max =250$ is better suited to the coastal region. The discrepancies found for both models demonstrate that the region in the south of the state has a set of benchmarks that differ around $88 \mathrm{~cm}$ from the determined models. The readjustment of the levelling network carried out by IBGE shows that this same region experienced changes of up to $60 \mathrm{~cm}$ between the old normal-orthometric heights and the current normal heights (IBGE 2019).

The information used in the production of the models, such as gravity acceleration, GGM, DTM, and in situ heights may have inconsistencies affecting the result of the validation. In this sense, another analysis was carried out removing 45 points that presented discrepancies greater than 50 $\mathrm{cm}$, including the above-mentioned benchmarks referred to the south of the state. The analysis is shown in Table 8.

Table 8: GPS/levelling evaluation with 246 points (m).

\begin{tabular}{l|c|c|c|c}
\hline nmax & Min & Max & Mean & SD \\
\hline 250 & -0.50 & 0.36 & -0.28 & 0.15 \\
\hline 720 & -0.50 & 0.37 & -0.30 & 0.14 \\
\hline
\end{tabular}

This evaluation resulted in standard deviations of $15 \mathrm{~cm}$ for the quasigeoid surface, using $X G M 2019$ e with $n \max =250$ and $14 \mathrm{~cm}$ for XGM2019e with nmax=720. Figure 14 shows the differences between the solutions.

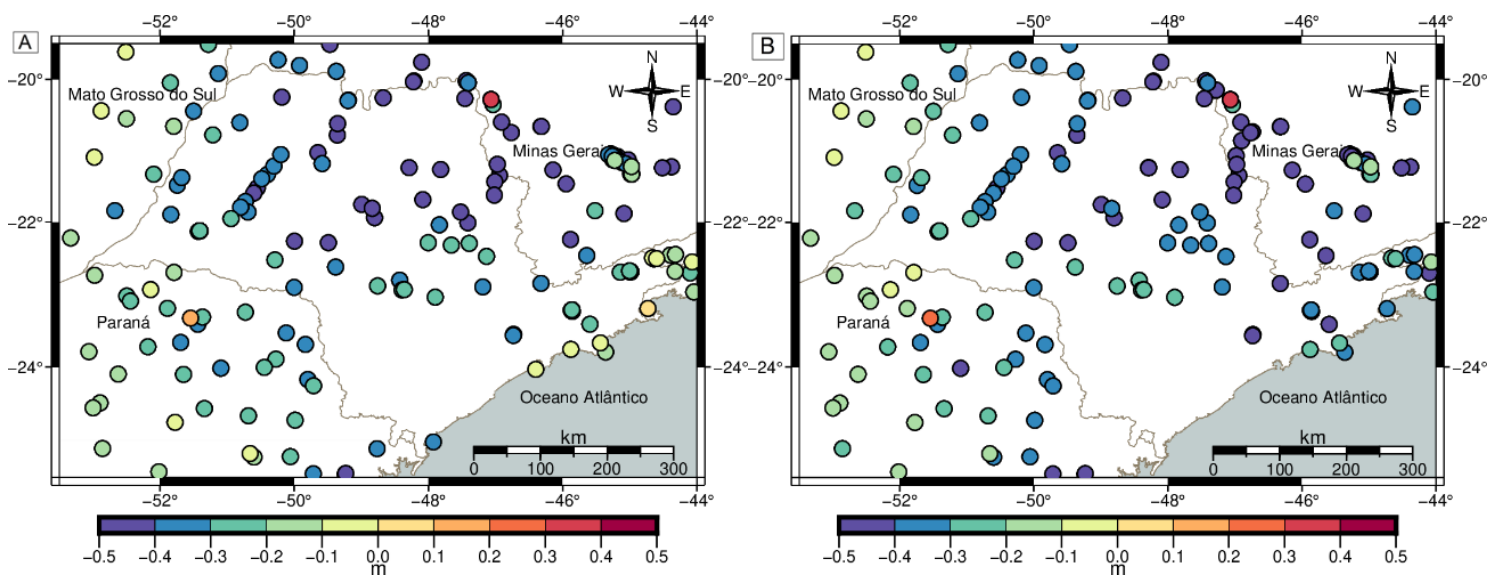

Figure 14: GPS/levelling with 246 points (A-nmax= 250; B:nmax= 720). 
Through the evaluations, it was concluded that the use of a GGM with degree and order 720 does not present advantages to the use of long wavelengths for the state of São Paulo. Despite the standard deviations of the analysis (Table 8), the levelling network and the GPS determinations are consistent between both solutions and the mean indicates that the quasigeoid surface with nmax $=250$ has a smaller systematic component. Moreover, a GGM expanded up to 720 contains terrestrial gravimetric information that will be doubly introduced to the model.

\section{Final Remarks}

The São Paulo geoid model, previously to the adoption of the normal height system, had an RMS difference of $\pm 14 \mathrm{~cm}$ to the GPS determinations on the levelling network (Guimarães et al. 2014). To achieve this consistency with the height system required a long work. Efforts have been made to produce and evaluate different geoid models, to determine $H$ for gravity densification, to improve the levelling networks, to choose the computation methodology, among others. In this context, modernizing the altimetric reference frame component adopting a new height system requires the identification of elements to be improved and the development of studies and methodologies.

The determination of the geoid and quasigeoid models was carried out based on updated gravimetric information from the state of São Paulo, with normal heights resulting from the 2018 BVRF realization and the information from the GGM XGM2019e. The results of the evaluation of the quasigeoid model of São Paulo demonstrate a consistency of $\pm 18 \mathrm{~cm}$ in the RMS difference, with 291 GPS determinations on the levelling network. Considering the terrestrial gravity points are compatible to a $5^{\prime}$ grid, equivalent to a 2160 degree and order, and the uncertainty up to 15 cm of GPS-levelling heights of the 2018 BVRF, the results are better than the current MAPGEO2015 difference $(30 \mathrm{~cm})$ and therefore the quasigeoid model is satisfactory. The region in the south of the state is characterized by gravimetric voids and by a set of benchmarks with significant discrepancies between normal and orthometric-normal heights. In this sense, the improvement of the quasigeoid model requires an improvement of the geodetic infrastructure in that region and the use of high-resolutions DTMs and altimetry data.

\section{ACKNOWLEDGEMENT}

Author 1 thanks the Coordenação de Aperfeiçoamento de Pessoal de Nível Superior (CAPES) for supporting this research. We acknowledge the Instituto Brasileiro de Geografia e Estatística (IBGE) for the significant contributions with information about the data. We also thank the reviewers and editors for their constructive criticism.

\section{AUTHOR'S CONTRIBUTION}


Author 1 performed the bibliography revision, the computation and the writing. Authors 2 and 3 advised the research. Author 4 helped in the computation process and with the Figures. All the authors helped to revise the paper.

\section{REFERENCES}

Albarici, F.L., Foroughi, I., Guimarães, G. do N., Santos, M., and Trabanco, J. 2019. A New Perspective for Physical Heights in Brazil. Bulletin of Geodetic Sciences, 25 (1), pp.0-3. DOI:https://doi.org/10.1590/s1982-21702019000100001.

Albarici, F.L., Guimarães, G.N., Foroughi, I., Santos, M., Luiz, J., and Trabanco, A. 2018. Separação Entre Geoide e Quase-Geoide: Análise das Diferenças Entre as Altitudes Normal-Ortométrica e Ortométrica Rigorosa [Separation Between Geoid and Quasi-Geoid: Analysis of the Diferences Between Normal-Orthometric and Rigorous Orthometric Heights]. Anuário do Instituto de Geociências - UFRJ, 41, pp.71-81. DOI:http://dx.doi.org/10.11137/2018_3_71_81 Resumo.

Amarante, R.R. 2012. Sistematização do processamento de dados gravimétricos aplicados à determinação do modelo geoidal [Systematization of gravimetric data processing applied to geoid model determination]. 183 f. Tese (Doutorado em Engenharia Civil). Faculdade de Engenharia Civil, Arquitetura e Urbanismo da Universidade Estadual de Campinas.

Andersen, O.B., Knudsen, P., Kenyon, S., and Holmes, S. 2014. Global and arctic marine gravity field from recent satellite altimetry (DTU13). 76th EAGE Conference and Exhibition 2014, pp.30493053. DOI:10.3997/2214-4609.20140897.

Barthelmes, F. 2013. Definition of functionals of the geopotential and their calculation from spherical harmonic models: theory and formulas used by the calculation service of the International Centre for Global Earth Models (ICGEM). Revised Edition, (Scientific Technical Report). Potsdam, Germany. DOI:https://doi.org/10.2312/GFZ.b103-0902-26.

Blitzkow, D., Campos, I., and De Freitas, S.R. 2004. Altitude : o que interessa e como equacionar? [Height: what does it matter and how to manage? ]. In: Anais do I Simpósio de Ciências Geodésicas e Tecnologia da Geoinformação. Recife.

Blitzkow, D., Matos, A.C.O.C., Carrupt, W.M., Nunes, M.A., Lengruber, N.V., Xavier, E.M.L.;, and Fortes, L.P.S. 2016. MAPGEO2015: O Novo Modelo De Ondulação Geoidal Do Brasil [MAPGEO2015: the New Geoidal Undulation Model of Brazil]. Revista Brasileira de Cartografia, 68 (1808-0936), pp.1873-1884.

Farr, T.., Rosen, P.A., Caro, E., Crippen, R., Duren, R., Hensley, S., Kobrick, M., Paller, M., Rodriguez, E., Roth, L., Seal, D., Shaffer, S., Shimada, J., Umland, J., Werner, M., Oskin, M., Burbank, D., and Alsdorf, D. 2008. Shuttle Radar Topography Mission: Mission to map the world. Reviews of Geophysics, 45 (2), pp.3-5. DOI:10.1029/2005RG000183.

Ferreira, V.G., De Freitas, S., and Heck, B. 2011. A separação entre o geoide e o quase geoide : uma análise no contexto brasileiro [The Separation Between Geoid and Quasigeoid: an Analysis in the Brazilian Context]. Revista Brasileira de Cartografia, 63, pp.39-50.

Ferreira, V.G. and De Freitas, S.R. 2010. Análise do termo de primeira ordem das séries de 
Molodenskii para o problema de valor de contorno da geodésia [An analysis of First-order Term of the Molodenskii's Series for Geodetic Boundary Value Problem]. Boletim de Ciências Geodésicas, 16 (4), pp.557-574. DOI:10.1590/s1982-21702010000400005.

Forsberg, R. 1984. A study of terrain reductions, density anomalies and geophysical inversion methods in gravity field modelling. Columbus, Ohio.: Scientific Report No5. Ohio State University.

Forsberg, R. 1997. Terrain effects in geoid computations. International Geoid School. Rio de Janeiro.

Forsberg, R. and Tcherning, C. 2008. An overview manual for the GRAVSOFT geodetic gravity field modelling programs. Copenhagen, Denmark.

Gruber, T., Zingerle, P., Pail, R., and Oikonomidou, X. 2019. High Resolution Gravity Field Models as Global Reference Surface for Height [online]. SIRGAS 2019. Available from: http://www.sirgas.org/fileadmin/docs/Boletines/Bol24/44_Gruber_et_al_2019_HR_Models .pdf [Accessed 15 Jan 2020].

Guimarães, G. do N., Blitzkow, D., Barzaghi, R., and Matos, A.C.O.C. de 2014. The computation of the geoid model in the state of São Paulo using two methodologies and GOCE models. Boletim de Ciências Geodésicas, 20 (1), pp.183-203. DOI:10.1590/s198221702014000100012.

Heck, B. 1989. On the non-linear geodetic boundary value problem for a fixed boundary surface. Bulletin Géodésique, 63, pp.57-67.

Hirt, C. and Rexer, M. 2015. 10,800 Spherical Harmonics. International Journal of Applied Earth Observation and Geoinformation, 39, pp.103-112. DOI:10.1016/j.jag.2015.03.001.Earth2014.

Hofmann-Wellenhof, B. and Moritz, H. 2006. Physical Geodesy. New York: SpringerWien.

IAG 2015. IAG Resolution (No. 1) for the definition and realization of an International Height Reference System (IHRS). München, Alemanha.

IBGE 2019. Reajustamento da Rede Altimétrica com Números Geopotenciais REALT-2018 [Readjustment of the Altimetric Network with Geopotential Numbers REALT-2018] [online]. Available from: https://biblioteca.ibge.gov.br/visualizacao/livros/liv101666.pdf.

Ince, S.E., Barthelmes, F., Reißland, S., Elger, K., Förste, C., Flechtner, F., and Schuh, H. 2019. ICGEM - 15 years of successful collection and distribution of global gravitational models, associated services, and future plans. Earth System Science Data, 11 (2), pp.647-674. DOI:10.5194/essd11-647-2019.

Kvas, A., Brockmann, J.M., Krauss, S., Schubert, T., Gruber, T., Meyer, U., Mayer-Gürr, T., Schuh, W.-D., Jäggi, A., and Pail, R. 2021. GOCO06s - a satellite-only global gravity field model. Earth System Science Data, 13 (1), pp.99-118. DOI:10.5194/essd-13-99-2021.

Luz, R.T. 2016. Cálculo de altitudes científicas e sua aplicação no reajustamento da Rede Altimétrica de Alta Precisão do Sistema Geodésico Brasileiro [Calculation of scientific altitudes and its application in the readjustment of the High Precision Altimetric Network of. Revista Brasileira de Geografia, 61 (1), pp.79-97. DOI:https://doi.org/10.21579/issn.25260375_2016_n1_art_4.

Mader, K. 1951. Das Newtonsche Raumpotential prismatischer Körper und seine Ableitungen bis 
zur dritten Ordnung. Österr Z Vermess Sonderhef, 11.

Molodensky, M., Yeremeyev, V., and Yurkina, M. 1962. Methods for study of the external gravitational field and figure of the earth. Transl. from Russian (1960): Israel Program for Scientific Translations, Jerusalem, 1962.

Moritz, H. 2000. Geodetic Reference System 1980. Journal of Geodesy, 74, pp.128-133. DOl:https://doi.org/10.1007/s001900050278.

Nagy, D. 1966. The Gravitational Attraction of a Right Rectangular Prism Attraction. Geophysics, 2 (5), pp.362-371.

Santana, T.A. and Dalazoana, R. 2020. Integração dos Referenciais Verticais Terrestre e Oceânico: Conceitos Relacionados, Projetos Desenvolvidos e Desafios [Integration of Land and Sea Vertical References: Involved Concepts, Developed Projects and Challenges]. Revista Brasileira de Cartografia, 72 (2), pp.345-364. DOI:10.14393/rbcv72n2-52611.

Severo, T.C., de Souza, S.F., Matsuoka, M.T., and Gehlen, A.K. 2013. Estudo das correções gravimétricas para altitudes físicas aplicadas aos desníveis da RAAP [Study of gravity corrections for physics heights applied to the height differences of RAAP]. Boletim de Ciencias Geodesicas, 19 (3), pp.472-497. DOI:10.1590/S1982-21702013000300008.

Silva, V.C., Blitzkow, D., Almeida Filho, F.G.V. de, Matos, A.C.O.C. de, and Bjorkstrom, I.M. 2020. Atualização da Estrutura Gravimétrica do Estado de São Paulo: Vínculo ao Sistema Gravimétrico de Referência [Gravimetric Structure Update of São Paulo State: Link to the Observations of the Gravimetric Reference System]. Anuário do Instituto de Geociências UFRJ, 43 (3), pp.215-226. DOI:10.11137/2020_3_215_226.

Tozer, B., Sandwell, D.T., Smith, W.H.F., Olson, C., Beale, J.R., and Wessel, P. 2019. Global Bathymetry and Topography at 15 Arc Sec: SRTM15+. Earth and Space Science, 6 (10), pp.1847-1864. DOI:10.1029/2019EA000658.

Tziavos, I.N. and Sideris, M.G. 2013. Topographic Reductions in Gravity and Geoid Modeling Ilias. pp.337-400. DOI:10.1007/978-3-540-74700-0.

Vu, D.T., Bruinsma, S., and Bonvalot, S. 2019. A high - resolution gravimetric quasigeoid model for Vietnam. Earth, Planets and Space. DOI:10.1186/s40623-019-1045-3.

Wenzel, H. 1985. Hochauflösende Kugelfunktionsmodelle für das Gravitationspotential der Erde. 137th ed.

Wong, L. and Gore, R. 1969. Accuracy of Geoid Heights from Modified Stokes Kernels. Geophysical Journal of the Royal Astronomical Society, 18 (1), pp.81-91. DOI:10.1111/j.1365246X.1969.tb00264.x.

Yakubu, C.I., Agyei, O.B., and Ferreira, V.G. 2019. Dynamics of the low- and high-degree components of a vertical datum: Towards the effect of omission error. Geophysical Journal International, 216 (1), pp.521-534. DOI:10.1093/gji/ggy453.

Yildiz, H., Forsberg, R., Ågren, J., Tscherning, C., and Sjöberg, L. 2012. Comparison of removecompute-restore and least squares modification of Stokes' formula techniques to quasi-geoid determination over the Auvergne test area. Journal of Geodetic Science, 2 (1). DOI:10.2478/v10156-011-0024-9.

Zingerle, P., Pail, R., Gruber, T., and Oikonomidou, X. 2020. The combined global gravity field model XGM2019e. Journal of Geodesy, 94 (7), pp.1-12. DOI:10.1007/s00190-020-01398-0. 